\title{
Décès de Sir Geoffrey Newman-Morris
}

Une des personnalités les plus connues et des plus populaires de la Croix-Rouge internationale, Sir Geoffrey Newman-Morris, est décédée le 19 octobre 1981.

Né en 1909, Sir Geoffrey fut, comme son père l'avait été précédemment, un chirurgien et un président de la Croix-Rouge australienne, et il accomplit avec distinction une double carrière, dans la médecine et dans la Croix-Rouge.

Il commença à exercer sa profession de médecin dans l'armée, car il fut mobilisé en 1939, au sortir de ses études, pour toute la durée de la deuxième guerre mondiale.

A partir de 1946, revenu à la vie civile, il exerça la chirurgie à l'Hôpital du Prince Henry, à Melbourne, et devint bientôt professeur de chirurgie à l'université de cette ville. Il fut en même temps très actif dans l'Association médicale d'Australie dont il fut tour à tour le secrétaire honoraire, puis le présidente fédéral (1966-73). Il présida également (1967-68) la Société médico-légale australienne. Il fut nommé viceprésident (1975-76), puis président (1976-77) de la Fédération des associations médicales d'Asie et d'Océanie. Il participa, à la tête de la délégation médicale australienne aux Assemblées de l'OMS de 1967, 68,72 , et 73 .

C'est en 1950 que Geoffrey Newman-Morris débuta dans la CroixRouge australienne, comme membre d'un comité de la Division de Victoria. Il fut élu au conseil de division dans la Croix-Rouge de Victoria en 1952, puis, en 1953, fut nommé au conseil exécutif de la Société nationale. En 1958, il devient le président national de la Croix-Rouge australienne, fonction qu'il garda jusqu'en 1978. Il fut un président extrêmement actif, patient et prévoyant, sachant stimuler et conseiller. Il visita toutes les différentes branches de la Croix-Rouge australienne et sa Société connut, sous sa direction, un développement remarquable.

Son activité s'étendit bientôt en dehors de l'Australie. Il participa aux Conseils des Gouverneurs de la Ligue des Sociétés de la CroixRouge, dès la $25^{\mathrm{e}}$ session de 1959 et à toutes les réunions successives jusqu'en 1977. Il conduisit la délégation de la Croix-Rouge australienne aux Conférences internationales de la Croix-Rouge, de la vingtième (à Vienne, en 1965) à la vingt-troisième (à Bucarest, en 1977).

Il occupa un des postes de vice-président de la Ligue des Sociétés de la Croix-Rouge de 1969 à 1973 et il fut le président de la Commission permanente de la Croix-Rouge internationale de 1973 à 1977. 
En plus de ses activités avec la Croix-Rouge, Geoffrey NewmanMorris appartint à l'Ordre de Saint-John, où il occupa une position éminente dans le prieuré australien.

De nombreuses médailles et décorations avaient été décernées à Geoffrey Newman-Morris, par la Croix-Rouge australienne aussi bien que par des Sociétés nationales étrangères, d'Asie, d'Europe ou d'Amérique, et il avait été nommé membre à vie de l'Alliance des Sociétés de la Croix-Rouge et du Croissant-Rouge d'URSS. En 1969, il avait été anobli par la reine Elizabeth et, en 1979, il avait reçu la médaille Henry Dunant, la plus haute distinction de la Croix-Rouge.

A tous ceux qui l'ont connu, Sir Geoffrey Newman-Morris laisse le souvenir d'un homme extrêmement actif, guidé par une intelligence lumineuse et par un profond sentiment d'humanité.

\section{Décès de Charles-André Schusselé}

La Ligue des Sociétés de la Croix-Rouge a eu le profond regret de perdre, le 17 février 1982, des suites d'un grave accident, Charles-André Schusselé, qui fut son dévoué collaborateur pendant trente-sept ans.

Il était né à Genève en 1916, d'une famille qui comptait parmi ses membres un des premiers délégués au CICR: son grand-père avait fait une mission, pendant la guerre franco-prussienne de $1870-71$, sous la direction du $\mathrm{D}^{\mathrm{r}}$ Louis Appia, l'un des fondateurs du CICR.

En se consacrant aux œuvres humanitaires après avoir obtenu sa licence en droit à l'Université de Genève, Ch.-A. Schusselé continuait donc une tradition familiale. Il présida, de 1938 à 1941, la section genevoise du "Mouvement de la Jeunesse suisse romande ". Entré au service de la Croix-Rouge suisse au début de la deuxième guerre mondiale, il fut le fondateur, en 1940-41, de son service "Secours aux enfants", qu'il dirigea jusqu'en 1943; il devint alors le chef du service central d'accueil de la Croix-Rouge suisse pour les enfants victimes de la guerre, il fonda le Centre Henry-Dunant en 1943 et s'occupa des quelque deux cent mille enfants étrangers victimes des événements qui furent reçus et hébergés en Suisse pendant ce deuxième conflit mondial.

En 1944, Ch.-A. Schusselé commença de travailler à la Ligue des Sociétés de la Croix-Rouge et demeura son collaborateur très actif jusqu'en 1981. Comme directeur du bureau "Croix-Rouge de la Jeunesse » (de 1952 à 1968), puis comme directeur des relations internationales de la Ligue, Ch.-A. Schusselé effectua d'innombrables mis- 